\title{
Al Based Assistance To Reduce Suicidal Tendency Among Youngsters
}

\author{
Bhupesh Rawat ${ }^{1}$, Ankur Singh Bist ${ }^{2}$, Mulyati ${ }^{3}$, Muhammad Fakhrezzy ${ }^{4}$, \\ Regina Dinda Octavyra ${ }^{5}$ \\ 1,2Graphic Era Hill University Bhimtal Campus \\ $3,4,5$ University of Raharja \\ 1,2Road Society Area, Oghal Bhatta, Clement Town, Dehradun, Uttarakhand 248002, India \\ 3,4,5Modern, Jl. Jenderal Sudirman No.40, Cikokol, Kec. Tangerang, Kota Tangerang, Banten \\ 15117 \\ e-mail: ankur1990bist@gmail.com¹, bhr222@gmail.com² ${ }^{2}$, mulyati@raharja.info ${ }^{3}$, \\ fahrezzy@raharja.info ${ }^{4}$, regina.dinda@raharja.info ${ }^{5}$
}

\section{To cite this document :}

Rawat, B., Bist, A.S., Mulyati, Fakhrezzy, M., \& Octavyra, R.D. (2023) Al Based Assistance To Reduce Suicidal Tendency Among Youngsters. Aptisi Transactions on Management (ATM), 7(2), 105-112.

DOI :

https://doi.org/10.33050/atm.v7i2.1829

\begin{abstract}
Suicidal tendency among youngsters is one of emerging issue in society. This not only results in loss of life but also has disruptive psychosocial and adverse socio-economic effects. It accounts for $1.4 \%$ of all deaths. It is also reported that men die more than women. If we look at male to female ratio regarding suicide death, then it is 1.5 to 1 and is highest in richest countries. Each year, approximately 800,000 people die by suicide worldwide. Fast life style, academic pressure, relationships, drug addiction etc, are major causes of this. This is exacerbated by the presence of new factors that arise as a result of the COVID-19 outbreak, which puts new pressures on society, which of course worsens the mental condition of today's society.Governments and NGOs are highly concerned about it. In this paper, we are concerned about the role of technology to prevent it. We will discuss how artificial intelligence can help in keeping the wellbeing of the mental state of human beings. Our focus would be on use of artificial intelligence in predicting and preventing suicide attempt. We will share our perspective on how other techniques excluding Al can help to alleviate this menace.Al based applications are playing a vital role to assist mental health. Our purpose is to study the role of $A$ l in mental health.
\end{abstract}

Keywords: Al, Mental Health, App, Life style.

\section{Introduction}

Suicide occurs more often in older than in younger people but is still one of the leading causes of death in late childhood and adolescence worldwide. This not only results in loss of life but also has disruptive psychosocial and adverse socio-economic effects[1].from the perspective of public mental health, suicide is the main concern among youth today. It accounts for $1.4 \%$ of all deaths. It is also reported that men die more than woman. If we look at male to female ratio regarding suicide death, then it is 1.5 to 1 and is highest in richest countries. Each year, approximately 800,000 people die by suicide worldwide[1].Suicide attempt is an action intended to deliberately end one's own life[2]. The most common method among youth is typically overdose or ingestion, followed by hanging/suffocation and the use of a sharp object[3], [4]. Suicide is second major cause of death among youth. it is the tenth leading cause of death among all age groups[5]. There are several reasons for a person to commit suicide such as failure in exam, 
loosing job, broken relationships among others. There are numerous counter measures that can be used to prevent it. One can realize the seriousness of situation from the earlier given information. This paper is organized as follows: firstly, A discussion on how suicide mortality rate can be reduced by keeping healthy mental state[6]. Secondly, we will discuss about how technology can help in keeping the wellbeing of mental state of human being wherein our focus would be on use of artificial intelligence in predicting and preventing suicide attempt. In the third section, we will share our perspective on how other techniques excluding Al can help to alleviate this menace[7].For example sentimental analysis technique has potential to sense the mood and behavior of a person who is going to commit suicide and will alert before hand in case of any such incident.

\section{Research Method}

\subsection{Mental Health}

Health is one of the prime concerns of human life. Mental health is ignored in normal cases but it's a severe concern. There is lots of research going on mental health[8]. Our purpose is to understand the role of Artificial Intelligence for mental health wellness. Next section is to understand $\mathrm{Al}$ in mental health.

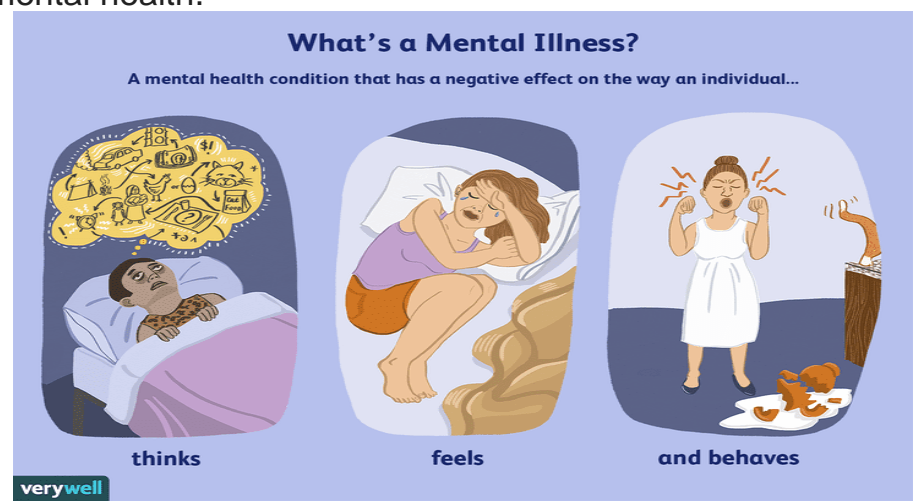

Figure1: Mental Illness

\subsection{Al in Mental health}

$\mathrm{Al}$ is playing a vital role to provide mental wellness[9]. Al based applications are available that provide various triggers:

1. Al enabled gadgets and app to monitor workout (Indirect mental wellness monitoring)

2. Al enabled chat bots for depression counseling

3. Al enabled app to connect with experts based on cause of depression

Lots of research articles have been written to find out features that may locate depression based on voice and facial features[10]-[12].

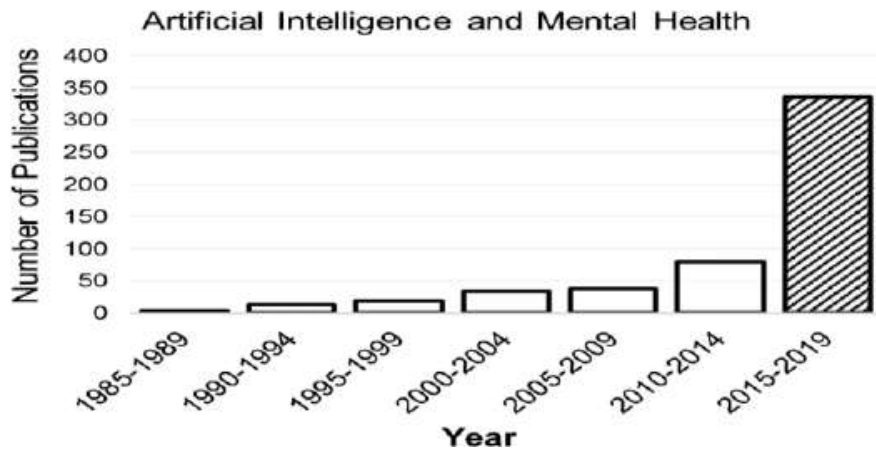

Figure2:Al and mental health publications 


\section{Result and Discussion}

Due to lockdown, people were not able to go out to do their core tasks and had to complete it within the confines of their home. This leads to working on mobile and computer which results in increased screen time and gives rise to several types of mental diseases. The youngster could not seek help from therapists and doctors due to lockdown[13], [14]. To fill this gap, many apps emerged in the market that provided mental health solutions online at the comfort of home. This section discusses various apps that are widely used by youngsters to seek help for their mental health.

\subsection{Al based Mobile Apps for mental health \\ 3.1.1 Wysa}

There are numerous conversational chatbots based on artificial intelligence available online for users suffering any sort of mental illness[15]. One of the popular apps is Wysa which is an Al based conversational chatbot that has been trained using 100 million odd conversations to understand user input[16]-[18]. The app makes use of widely used techniques such as CBT(cognitive behavioral therapy), DBT(dialectical behavioral therapy) and meditation support for user with depression, stress, anxiety, sleep and other mental health needs. According to a survey, it is reported that the app saw an $80 \%$ rise in installation as compared to last year. The good thing about this app is that it is free of cost and can be used in any platform be it windows or android[19], [20].

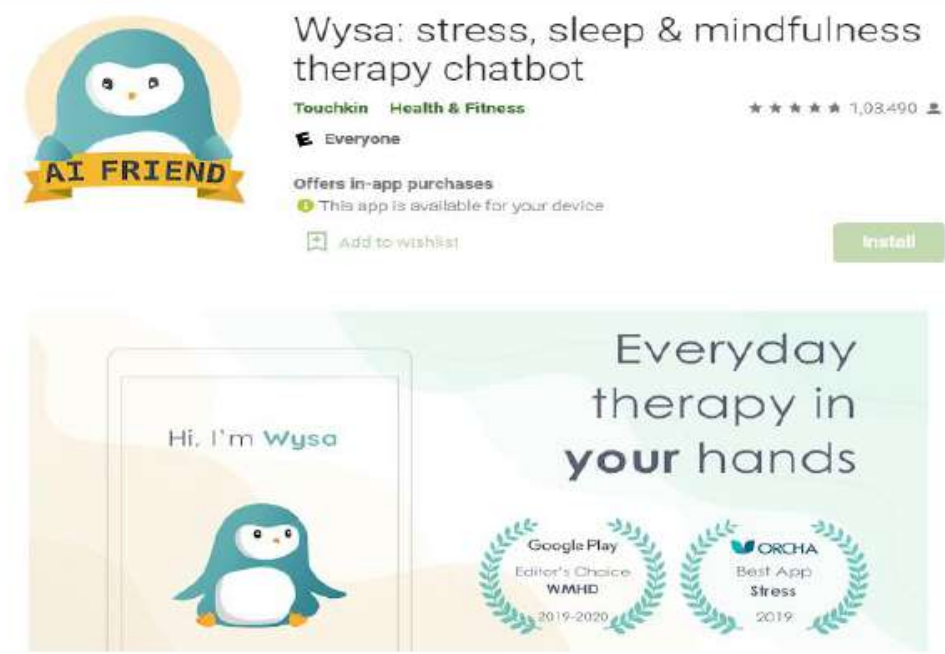

Figure 3: Wysa: stress, sleep \& mindfulness therapy chatbot

This app is designed to listen, support and encourage people suffering from mental diseases. However, it is important to note that, vyasa is not intended for providing diagnosis, treatment or cure of a condition or disease or disorders. Wysa cannot and will not offer advice on unrecognizable issues[21], [22]. The app also makes sure that privacy of help seekers is kept confidential which means all the conversation between chatbot, and user will be anonymous. Another important aspect is that most of the time users do not want to fix their problem and just would like to listen to them with patience and not to judge. In addition to building skills, Al-based conversations are also an easy, private way to practice these skills when learnt in therapy.

\subsubsection{Woebot}

Woebot helps a user think pragmatically through various situations by providing step-bystep guidance using CBT. With the help of this software a user can learn more and more about himself/herself using mood tracking[23], [24]. 


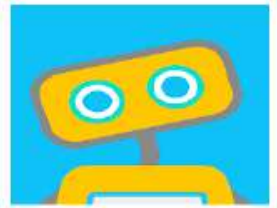

Woebot: Your Self-Care Expert

woebot Health Medical $\star \star \star \star \star \star \star 70,996=$

$3+$

O This app is avalable for your devic

回 Add to Wishlist

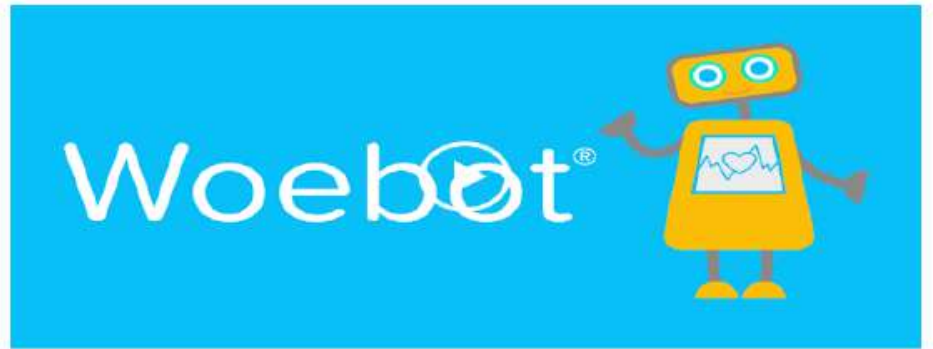

Figure 3: Woebot:Self-care expert

This year, the app launched a COVID-19 program called Perspectives, where it provides more guided meditation techniques and practical tips on overcoming cabin fever or connecting with others while social distancing. There were also themes added to deal with grief and economic hardships[25].

\subsubsection{Happify}

This is another useful app which is used widely by users suffering from mental health. What makes this app unique is its distinctive approach through various types of games and other exercises led by digital Al coaches. Recently a new feature was added to the app referred to as 'adherence fidelity' for which it was also granted patent[26]-[28]. The new feature is based on $\mathrm{NLP}$ (natural language processing) which alerts the user when he moves away from the intention of activity and gently guides them to be more adherent. This feature has helped attain maximum health outcomes. $86 \%$ of people who use Happify regularly report feeling better about their lives in 2 months!Happify's science-based activities and games can help reduce stress, overcome negative thoughts, and build greater resilience by providing effective tools and programs to improve emotional well-being[29], [30].

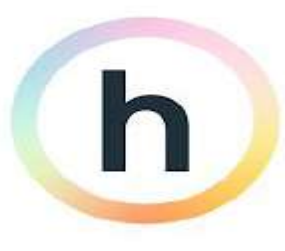

\section{Happify \\ Happify, Inc. Health \& Fitness}

$3+$

Contains Ads - Offers in-app purchases

(3) This app is avaliable for your device

ఉ Add to Wishlist
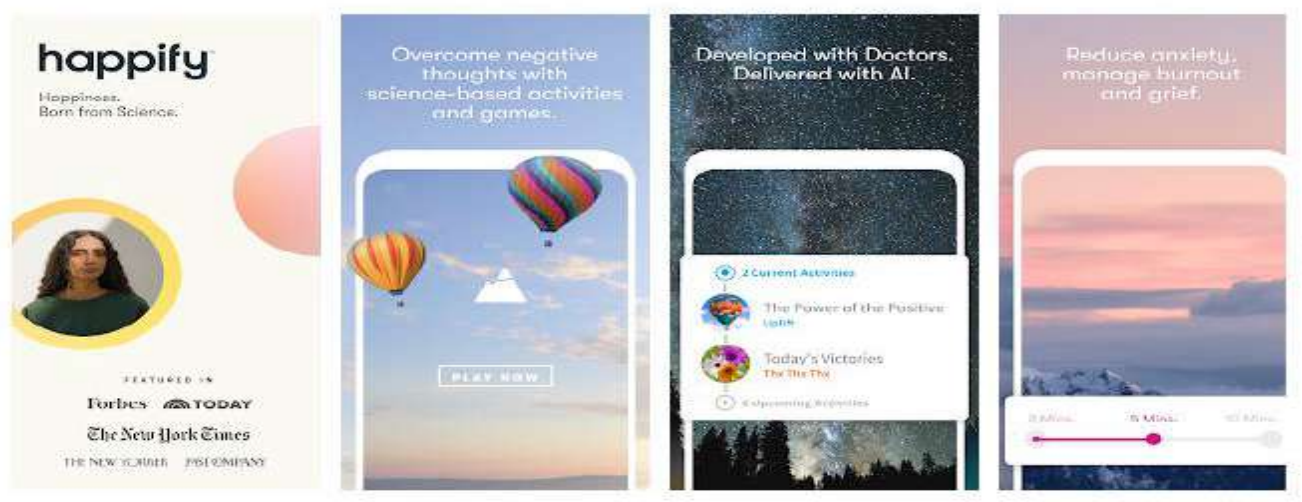

Figure 4: Woebot: Self-care expert 
The following are some of the benefits offered by Woebot app to its users:

${ }^{*}$ Conquering negative thoughts

${ }^{*}$ Coping better with stress

* Building self-confidence

* Fueling your career success

* Achieving mindfulness through meditation

\section{Conclusion}

Mental health is one of the serious problems. with accounts for $1.4 \%$ of all deaths. And also reported that men die more than women. If we look at male to female ratio regarding suicide death, then it is 1.5 to 1 and is highest in richest countries. Each year, approximately 800,000 people die by suicide worldwide.Al is helping to crack the issue of mental health in a way. There are lots of applications too as discussed in the paper.

Al with human assisted protocol is the best way to deal with it.Al based applications are available that provide various triggers such as $\mathrm{Al}$ enabled gadgets and apps to monitor workout (Indirect mental wellness monitoring), Al enabled chat bots for depression counseling and enabled apps to connect with experts based on causes of depression. With the help of Al, it is hoped that it can reduce the percentage of stress felt by teenagers today, where covid makes us more isolated. With this tool we can still get the necessary health assistance and with the installation of devices on gadgets that we usually use, it makes it easier to use. Not only technology but overall assessment at the level of values and education will kill this issue.

Unfortunately, in this study, there are still problems with Al devices that still need development. With current Al devices, they are still unable to diagnose mental health problems experienced by patients, and are only able to provide simple treatments for disorganized diseases. This makes Al still less effective, so that on the next opportunity, research on the development of $\mathrm{Al}$ that is able to diagnose patients' mental illness is what we plan to do, with our future developments, it is hoped that patients will get appropriate and more effective treatment with the disease they have. . which will certainly reduce the number of suicides in society, especially among teenagers. 


\section{References}

[1] "https://www.frontiersin.org/articles/10.3389/fpsyt.2018.00540/full, Last visited 22 October 2021. Google Search." https://www.google.com/search?q=https\%3A\%2F\%2Fwww.frontiersin.org\%2Farticles\%2 F10.3389\%2Ffpsyt.2018.00540\%2Ffull\%2C+Last+visited+22+October+2021.\&hl=en\&ei =DuTrYYWPAv6SseMP8ZGQ6A8\&ved=0ahUKEwiFztzEmsX1AhV-

SWwGHfEIBP0Q4dUDCA4\&uact=5\&oq=https\%3A\%2F\%2Fwww.frontiersin.org\%2Fartic les\%2F10.3389\%2Ffpsyt.2018.00540\%2Ffull\%2C+Last+visited+22+October+2021.\&gs Icp=Cgdnd3Mtd2|6EANKBAhBGAFKBAhGGABQugdYugdgnBBoAXAAeACAAWCIAWC SAQExmAEAoAECoAEBwAEB\&sclient=gws-wiz (accessed Jan. 22, 2022).

[2] P. Hendriyati, F. Agustin, U. Rahardja, and T. Ramadhan, "Management Information Systems on Integrated Student and Lecturer Data," Aptisi Transactions on Management (ATM), vol. 6, no. 1, pp. 1-9, Jul. 2021, doi: 10.33050/ATM.V6I1.1527.

[3] "World Health Organization (WHO). (2017). Disease and injury country mortality estimates, 2000-2015 [Data files]. Retrieved September 23, 2017 from http://www.who.int/healthinfo/global_burden. - - Google Search." https://www.google.com/search?q=World+Health+Organization+\%28WHO\%29.+\%2820 $17 \% 29$. Disease+and+injury+country+mortality+estimates $\% 2 \mathrm{C}+2000 \% \mathrm{E} 2 \% 80 \% 932015$ +\%5BData+files\%5D.+Retrieved+September+23\%2C+2017+from+http\%3A\%2F\%2Fww w.who.int\%2Fhealthinfo\%2Fglobal_burden.\&hl=en\&ei=NePrYbytNZ2eseMPI8q9gAo\&ve $\mathrm{d}=0$ ahUKEwj8m9PdmcX1AhUdT2wGHRdID6AQ4dUDCA4\&oq=World+Health+Organiza tion+\%28WHO\%29.+\%282017\%29.+Disease+and+injury+country+mortality+estimates $\% 2 \mathrm{C}+2000 \%$ E2\%80\%932015+\%5BData+files\%5D.+Retrieved+September+23\%2C+20 17+from+http\%3A\%2F\%2Fwww.who.int\%2Fhealthinfo\%2Fglobal_burden.\&gs_lcp=Cgd nd3Mtd2I6EAxKBAhBGABKBAhGGABQAFgAYABoAHAAeACAAQCIAQCSAQCYAQA \&sclient=gws-wiz (accessed Jan. 22, 2022).

[4] "Suicide attempt is an action intended to deliberately end one's own life. The most common method among youth is typically overdose or ingestion, followed by hanging/suffocation and the use of a sharp object. - Google Search." https://www.google.com/search?q=Suicide+attempt+is+an+action+intended+to+deliberat ely+end+one\%27s+own+life.+The+most+common+method+among+youth+is+typically+ overdose+or+ingestion $\% 2 \mathrm{C}+$ followed+by+hanging $\% 2$ Fsuffocation+and+the+use+of+a+s harp+object.\&hl=en\&ei=NePrYbytNZ2eseMPI8q9gAo\&ved=0ahUKEwj8m9PdmcX1AhU dT2wGHRdID6AQ4dUDCA4\&uact $=5 \&$ oq $=$ Suicide + attempt+is + an +action+intended + to $+d$ eliberately+end+one\%27s+own+life.+The+most+common+method+among+youth+is+ty pically+overdose+or+ingestion\%2C+followed+by+hanging\%2Fsuffocation+and+the+use + of +a+sharp+object.\&gs_lcp=Cgdnd3Mtd2I6EANKBAhBGAFKBAhGGABQyQtYyQtgxx NoAXAAeACAAQCIAQCSAQCYAQCgAQKgAQHAAQE\&sclient=gws-wiz (accessed Jan. 22, 2022).

[5] "Center for Disease Control and Prevention (CDC). (2017). Web basedInjury Statistics Query and Reporting System [Data-file]. Retrieved January 26, 2017 from: https://www.cdc.gov/injury/wisqars/fatal_injury_reports.html. - Google Search." https://www.google.com/search?q=+Center+for+Disease+Control+and+Prevention+\%28 CDC\%29.+\%282017\%29.+Web+basedlnjury+Statistics+Query+and+Reporting+System $+\% 5$ BData-

file\%5D.+Retrieved+January+26\%2C+2017+from\%3A+https\%3A\%2F\%2Fwww.cdc.gov \%2Finjury\%2Fwisqars\%2Ffatal_injury_reports.html.\&hl=en\&ei=7ePrYaPDJpKaseMPlp

W_6Ag\&ved=0ahUKEwjj7aK1msX1AhUSTWwGHZbKD40Q4dUDCA4\&uact=5\&oq=+Ce nter+for+Disease+Control+and+Prevention+\%28CDC\%29.+\%282017\%29.+Web+based Injury+Statistics+Query+and+Reporting+System+\%5BData-

file\%5D.+Retrieved+January+26\%2C+2017+from\%3A+https\%3A\%2F\%2Fwww.cdc.gov \%2Finjury\%2Fwisqars\%2Ffatal_injury_reports.html.\&gs_lcp=Cgdnd3Mtd2l6EANKBAhB GAFKBAhGGABQhQtYhQtg8RFoAXAAeACAAQCIAQCSAQCYAQCgAQKgAQHAAQE \&sclient=gws-wiz (accessed Jan. 22, 2022).

[6] W. Setyowati and A. Sofingi, "Determinants of Employee Performance with Work Motivation as an Intervening Variable at the Semarang City Search and Rescue Office," 
Aptisi Transactions on Management (ATM), vol. 6, no. 1, pp. 19-29, Jul. 2021, doi: 10.33050/ATM.V6l1.1638.

[7] A. Pamungkas, A. Suharko, ... D. A.-A. T. on, and undefined 2023, "Analysis of the Effect of Quality, Service Price and Satisfaction on Patients and Their Impact on Visits to Exclusive Dental Clinics in South Jakarta," ijc.ilearning.co, Accessed: Jan. 22, 2022. [Online]. Available: https://www.ijc.ilearning.co/index.php/ATM/article/view/1747

[8] F. Septiyana, M. Shihab, ... H. K.-... on M. (ATM, and undefined 2023, "Analysis of the Effect of Product Quality, Price Perception and Social Value on Purchase Decisions for Lampung Tapis Fabrics," ijc.ilearning.co, Accessed: Jan. 22, 2022. [Online]. Available: https://www.ijc.ilearning.co/index.php/ATM/article/view/1744

[9] K. Dayri Prawira, B. P. Kusumo Bintoro, R. Hadis, and Y. Anggraini Terah, "Analysis of Factors Affecting Customer Satisfaction at PT. OSO Gallery," adi-journal.org, vol. 3, no. 2, pp. 172-183, 2022, doi: 10.34306/ajri.v3i2.531.

[10] R. Sturgill, M. Martinasek, ... T. S.-J. F., and undefined 2021, "A Novel Artificial Intelligence-Powered Emotional Intelligence and Mindfulness App (Ajivar) for the College Student Population During the COVID-19," formative.jmir.org, Accessed: Jan. 22, 2022. [Online]. Available: https://formative.jmir.org/2021/1/e25372/

[11] F. Sahlan, F. Hamidi, M. Z. Misrat, M. H. Adli, S. Wani, and Y. Gulzar, "Prediction of Mental Health Among University Students," journals.iium.edu.my, vol. 7, no. 1, 2021, Accessed: Jan. 22, $2022 . \quad$ [Online].

https://journals.iium.edu.my/kict/index.php/IJPCC/article/view/225

[12] M. T. Sqalli et al., "Perspectives on Human-Al Interaction Applied to Health and Wellness Management: Between Milestones and Hurdles," Springer, pp. 41-51, 2021, doi: 10.1007/978-3-030-67303-1 4.

[13] J. Rahmad, S. Suwandi, ... C. S.-A. J. on R., and undefined 2022, "Analysis of The Effect of Community's Role in CSR Activities on The Image of The Company of Minarak Brantas Gas, Inc.," adi-journal.org, Accessed: Jan. 22, 2022. [Online]. Available: https://www.adijournal.org/index.php/ajri/article/view/530

[14] L. Faza, P. Agustini, ... S. M.-A. J. on R., and undefined 2022, "Motives For Purchase of Skin Care Product Users (Phenomenology Study on Women in DKI Jakarta)," adijournal.org, Accessed: Jan. 22, 2022. [Online]. Available: https://www.adijournal.org/index.php/ajri/article/view/520

[15] "Top Al-based Mental Health Apps Of 2020." https://analyticsindiamag.com/top-ai-basedmental-health-apps-of-2020/ (accessed Jan. 22, 2022).

[16] V. M. O'Keefe, R. P. Tucker, A. B. Cole, D. W. Hollingsworth, and L. R. R. Wingate, "Understanding Indigenous Suicide Through a Theoretical Lens: A Review of General, Culturally-Based, and Indigenous Frameworks," Transcultural Psychiatry, vol. 55, no. 6, pp. 775-799, Dec. 2018, doi: 10.1177/1363461518778937.

[17] J. D. Ivanich et al., "Social Network Differences Between American Indian Youth Who have Attempted Suicide and Have Suicide Ideation," Community Mental Health Journal, Jul. 2021, doi: 10.1007/S10597-021-00857-Y.

[18] A. B. Cole et al., "Alcohol use and the interpersonal theory of suicide in American Indian young adults," Journal of Ethnicity in Substance Abuse, vol. 19, no. 4, pp. 537-552, Nov. 2020, doi: 10.1080/15332640.2018.1548320.

[19] V. O'Keefe, R. Tucker, ... A. C.-T., and undefined 2018, "Understanding indigenous suicide through a theoretical lens: A review of general, culturally-based, and indigenous frameworks," journals.sagepub.com, Accessed: Jan. 22, 2022. [Online]. Available: https://journals.sagepub.com/doi/abs/10.1177/1363461518778937

[20] V. O'Keefe, G. R.-P. services, and undefined 2017, "Suicide among American Indian/Alaska Native military service members and veterans.," psycnet.apa.org, Accessed: Jan. 22, 2022. [Online]. Available: https://psycnet.apa.org/record/2017-34654004

[21] C. E. Holliday, M. Wynne, J. Katz, C. Ford, and C. Barbosa-Leiker, "A CBPR approach to finding community strengths and challenges to prevent youth suicide and substance abuse," Journal of Transcultural Nursing, vol. 29, no. 1, pp. 64-73, Jan. 2018, doi: $10.1177 / 1043659616679234$.

[22] K. Standish, "A coming wave: suicide and gender after COVID-19," Journal of Gender Studies, pp. 114-118, 2020, doi: 10.1080/09589236.2020.1796608. 
[23] D. D'Hotman, E. L.-B. H. \& C. Informatics, and undefined 2020, "Al enabled suicide prediction tools: a qualitative narrative review," ncbi.nlm.nih.gov, Accessed: Jan. 22, 2022. [Online]. Available: https://www.ncbi.nlm.nih.gov/pmc/articles/PMC7549453/

[24] J. Ivanich, V. O'Keefe, E. Waugh, L. T.-... mental health journal, and undefined 2021, "Social network differences between American Indian youth who have attempted suicide and have suicide ideation," Springer, Accessed: Jan. 22, 2022. [Online]. Available: https://link.springer.com/article/10.1007/s10597-021-00857-y

[25] I. H. Stanley, M. A. Hom, A. J. Gallyer, J. S. Gray, and T. E. Joiner, "Suicidal behaviors among American Indian/Alaska Native firefighters: Evidence for the role of painful and provocative events," journals.sagepub.com, vol. 57, no. 2, pp. 275-287, Apr. 2020, doi: $10.1177 / 1363461519847812$.

[26] A. Cole, E. Leavens, E. Brett, ... S. L.-J. of ethnicity in, and undefined 2020, "Alcohol use and the interpersonal theory of suicide in American Indian young adults," Taylor \& Francis, Accessed: Jan. 22, $2022 . \quad$ [Online]. Available: https://www.tandfonline.com/doi/abs/10.1080/15332640.2018.1548320

[27] M. Ai, J. Wang, J. Chen, W. Wang, ... X. X.-P., and undefined 2019, "Plasma brain-derived neurotrophic factor (BDNF) concentration and the BDNF Val66Met polymorphism in suicide: a prospective study in patients with," ncbi.n/m.nih.gov, Accessed: Jan. 22, 2022. [Online]. Available: https://www.ncbi.nlm.nih.gov/pmc/articles/PMC6614583/

[28] A. Kelley, D. Restad, J. K.-P. services, and undefined 2018, "A public health approach: Documenting the risk and protective factors of suicide ideation in one American Indian community.," psycnet.apa.org, Accessed: Jan. 22, 2022. [Online]. Available: https://psycnet.apa.org/record/2018-37731-012

[29] Z. Li et al., "The prevalence of suicidal ideation and suicide attempt in patients with rheumatic diseases: a systematic review and meta-analysis," Psychology, Health and Medicine, vol. 23, no. 9, pp. 1025-1036, Oct. 2018, doi: 10.1080/13548506.2018.1476724.

[30] J. Ivanich and B. Teasdale, "Suicide Ideation among Adolescent American Indians: An Application of General Strain Theory," Deviant Behavior, vol. 39, no. 6, pp. 702-715, Jun. 2018, doi: 10.1080/01639625.2017.1304799. 